\title{
Changes in Fatty Acid Metabolism after Erythrocyte Peroxidation: Stimulation of a Membrane Repair Process
}

\author{
Bertram H. Lubin, Stephen B. Shohet, and David G. Nathan \\ From the Division of Hematology, Department of Medicine, Children's \\ Hospital Medical Center and the Department of Pediatrics, Harvard \\ Medical School, Boston, Massachusetts 02115
}

A B S T R A C T To study certain membrane repair processes in human erythrocytes, vitamin E-deficient cells were incubated with hydrogen peroxide. The incorporation of exogenous fatty acid and the transfer of fatty acid from phosphatidylcholine and neutral lipid into phosphatidylethanolamine were examined using radioactive fatty acids.

Hydrogen peroxide stimulated the incorporation of fatty acid into all membrane phospholipids. The specific activity of phosphatidylethanolamine was increased disproportionately.

The lipids of the membranes of erythrocytes were labeled with saturated and unsaturated fatty acid. When these erythrocytes were subsequently incubated with hydrogen peroxide, both types of fatty acid were transferred from superficial erythrocyte neutral lipids into phosphatidylethanolamine. However, the unsaturated fatty acids of phosphatidylethanolamine were subsequently altered by hydrogen peroxide, whereas the saturated fatty acids were not. The cumulative effect of these processes was a relative decrease in unsaturated fatty acid and an increase in saturated fatty acid in the phosphatidylethanolamine of the erythrocyte membrane.

The net effect of these events represents the operation of repair processes which distort the usual fatty acid composition of erythrocyte membranes in the presence of $\mathrm{H}_{2} \mathrm{O}_{2}$. This distortion may contribute to membrane permeability changes which occur during peroxide ex-

Dr. Lubin's present address is Children's Hospital of Philadelphia, 18th and Bainbridge Streets, Philadelphia, Pa. 19146.

Dr. Shohet is a Fellow of the Medical Foundation, Inc.; his present address is Moffitt Hospital, University of California Medical Center, Parnassus Avenue, San Francisco, Calif. 94122. Dr. Nathan is the recipient of U. S. Public Health Service Career Development Award AM-35361.

Received for publication 21 July 1971 and in revised form 17 September 1971. posure and which precede the eventual hemolysis of these cells.

\section{INTRODUCTION}

Lipid peroxidation occurs when unsaturated fatty acids are exposed to a free radical generating system such as hydrogen peroxide (1). The presence of vitamin $E$ or a similar antioxidant will prevent this process (2).

Prelytic alterations in lipids have been reported in vitamin E-deficient red blood cells during incubation in the presence of a $\mathrm{H}_{2} \mathrm{O}_{2}$-generating system. In the vitamin E-deficient rat, Jacob and Lux have shown that membrane phosphatidylethanolamine $(\mathrm{PE})^{1}$ is significantly decreased during such incubation (3). In man, erythrocytes from patients with abetalipoproteinemia exhibited a prelytic loss of PE, phosphatidylserine (PS), and polyunsaturated fatty acids during exposure to $\mathrm{H}_{2} \mathrm{O}_{2}$ (4). Also in man, vitamin E-deficient erythrocytes from newborn infants exhibited lipid peroxidation as measured by the thiobarbituric acid reaction after incubation with $\mathrm{H}_{2} \mathrm{O}_{2}$ (5).

$\mathrm{PE}$ contains a high concentration of polyunsaturated fatty acids (6) and hence may be especially sensitive to lipid peroxidation. It has been shown that a significant renewal pathway for $\mathrm{PE}$ fatty acid involves the transfer of fatty acid from a superficial neutral lipid pool through phosphatidylcholine (PC) into $\mathrm{PE} \mathrm{(7).} \mathrm{Unlike} \mathrm{red}$ blood cell ( $R B C$ ) PC, RBC PE is not partially sustained by passive exchange with plasma $\mathrm{PE}$ since the latter is virtually undetectable (8).

The purpose of the studies reported here was to examine the renewal pathways for $\mathrm{RBC} P E$ when vitamin

\footnotetext{
${ }^{1}$ Abbreviations used in this paper: FA, fatty acid; KHB, Krebs-Henseleit buffer; PC, phosphatidylcholine; PE, phosphatidylethanolamine; PS, phosphatidylserine; RBC, red blood cell.
} 
E-deficient red blood cells were incubated with $\mathrm{H}_{2} \mathrm{O}_{2}$. The results demonstrated an increase in the incorporation of fatty acid into $\mathrm{RBC} \mathrm{PE}$, which was consistent with an $\mathrm{H}_{2} \mathrm{O}_{2}$-stimulated membrane "repair process." However, saturated fatty acid accumulated in PE to a much greater extent than unsaturated fatty acid. This remodeling of membrane fatty acid composition may contribute to membrane stiffness and permeability changes and hence to the rheologic abnormalities of peroxide-injured cells.

\section{METHODS}

\section{Materials}

Crystallized human serum albumin for the incorporation of labeled fatty acids was obtained from Dade Reagents Inc., American Hospital Supply Corp., Evanston, Ill. Linoleic acid-1 $-{ }^{14} \mathrm{C}$, palmitic acid-9,10- ${ }^{8} \mathrm{H}$, and arachidonic acid$1{ }^{14} \mathrm{C}$ were obtained from Applied Science Laboratories Inc., State College, $\mathrm{Pa}$. Defatted albumin for the removal of superficial red cell fatty acid was prepared from human fraction V supplied by the Massachusetts State Department of Health by equilibration with activitated charcoal as described by Chen (9). $\mathrm{H}_{2} \mathrm{O}_{2}$, as Superoxol, was obtained from Fisher Scientific Company, Pittsburgh, $\mathrm{Pa}$.

\section{Cell collection and preparation}

Heparinized peripheral venous blood was obtained from children with clinical histories compatible with vitamin $E$ deficiency (10-12). Samples exhibiting greater than $80 \%$ hemolysis in the peroxide hemolysis test determined by the method of Rose and Gyorgy were used for further studies (13). The red cells were separated from the serum and residual leukocytes and platelets with multiple washes in Krebs-Henseleit buffer (KHB) at $\mathrm{pH} 7.4$ as previously described (14). When reconstituted to an hematocrit of $6 \%$, the white blood cell count was less than 100 cells $/ \mathrm{ml}^{3}$.

\section{Lipid analysis}

Erythrocyte lipids were extracted and separated according to methods previously published (14). Major lipid components were isolated by thin-layer chromatography on Silica Gel $\mathrm{H}$ plates obtained from Brinkman Instruments Inc., Westbury, N. Y. Appropriate spots were identified by iodine staining. After complete evaporation of the iodine, they were scraped from the plate, and determinations of lipid phosphorous and radioactivity were made on fractions of sonicated suspensions of this material by the direct methods of Parker and Peterson (15) and Snyder and Stephens (16). Methyl esters were prepared using boron trifluoride (17). Gas-liquid chromatography was performed by methods similar to those of Dodge and Phillips (6) using an $8 \mathrm{ft}$ glass column packed with $7 \%$ EGSS-X on Gas-Chrom P, 100-120 mesh, with a hydrogen flame ionization detector. The carrier gas flow rate was $30 \mathrm{ml} / \mathrm{min}$, and the column temperature was maintained at $190^{\circ} \mathrm{C}$ and the injector at $215^{\circ} \mathrm{C}$. Retention times were determined daily by comparison with a known standard mixture of fatty acid methyl esters. Peak areas were calculated by triangulation and were corrected in proportion to the molecular weights of the component fatty acids. Butylated hydroxytoluene which was usually added as an antioxidant emerged from the column with a retention time similar to that of methyl myristate, and thus myristic acid was not independently determined. The gas-liquid chromatography methods used here were not capable of distinguishing the geometric isomers of unsaturated fatty acids or of separately resolving dimethylacetal derivatives of plasmalogens (6).

\section{Radioactivity determinations}

Radioactivity measurements were made in a Packard Tri Carb, model 3370 scintillation spectrometer. Buhler's solution was used as a scintillating fluid (18). ${ }^{3} \mathrm{H}$ and ${ }^{14} \mathrm{C}$ radioactivities were separated as previously described (14). Quench corrections were made for each sample by the use of individual internal standards. Radioactive fatty acids were purified by thin-layer chromatography (19) before being complexed with defatted albumin (14).

\section{Experimental procedures}

A. Incorporation of radioactive fatty acid into red cell phosphatides. Washed red cells (4\% hematocrit in KHB) were incubated at $37^{\circ} \mathrm{C}$ in the presence of radioactive fatty acids bound to albumin (final concentration of albumin 300

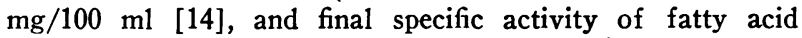
albumin complexes: arachidonic acid-14 $\mathrm{C}, 17 \mathrm{mCi} / \mathrm{mmole}$, and palmitic acid- ${ }^{3} \mathrm{H}, 27 \mathrm{mCi} / \mathrm{mmole}$ ) with an equal volume of $\mathrm{KHB}$ with or without $2 \% \mathrm{w} / \mathrm{v} \mathrm{H}_{2} \mathrm{O}_{2}$. The reaction was terminated by three washes at $4^{\circ} \mathrm{C}$ with $\mathrm{KHB}$ containing $5 \%$ of a solution saturated with thymol (5). The lipids of the cells were then extracted, separated, and analyzed as in Methods sections 3 and 4.

$B$. Transfer of fatty acids into phosphatidylethanolamine. Red cells were prepared and incubated with saturated and unsaturated fatty acids without $\mathrm{H}_{2} \mathrm{O}_{2}$ as above. After a 2 $\mathrm{hr}$ incubation, the cells were washed free of unincorporated fatty acid with $\mathrm{KHB}$ and reincubated at a final hematocrit of $4 \%$ with an equal volume of $2 \% \mathrm{H}_{2} \mathrm{O}_{2}$ in $\mathrm{KHB}$ or with an equal volume of $\mathrm{KHB}$. At each time period thereafter, KHB-containing thymol was added, the cells were centrifuged, the supernate was discarded, and the cell lipids were extracted and analyzed as above.

C. Transfer of fatty acid into phosphatidylethanolamine after removal of superficial membrane lipid pool. To assess the role of the neutral lipid in the repair process, cells were labeled without the presence of $\mathrm{H}_{2} \mathrm{O}_{2}$ as in Methods section $5 \mathrm{~A}$ using ${ }^{8} \mathrm{H}$-labeled palmitic acid. Palmitic acid was used in these studies because, being fully saturated, it was unlikely that it would undergo peroxidative degeneration. The radioactivity labeled fatty acid in the superficial fatty acid (FA) pool was then replaced with nonradioactive fatty acid as follows: the media were removed by centrifugation, and the cells were washed twice with cold isotonic $\mathrm{NaCl}$. The cells were then washed twice with a cold $1 \%$ solution of defatted human serum albumin in isotonic $\mathrm{NaCl}$. The cells were then reincubated with 10 vol of autologous serum to reestablish a nonradioactive superficial membrane neutral lipid pool (14). The cells were finally washed in fresh isotonic $\mathrm{NaCl}$ and reincubated as in Methods section $5 \mathrm{~B}$.

\section{RESULTS}

Quantitative changes in red blood cell phospholipids after incubation in hydrogen peroxide for $1 \mathrm{hr}$. A slight $(6-16 \%)$ loss of total phospholipid before lysis 

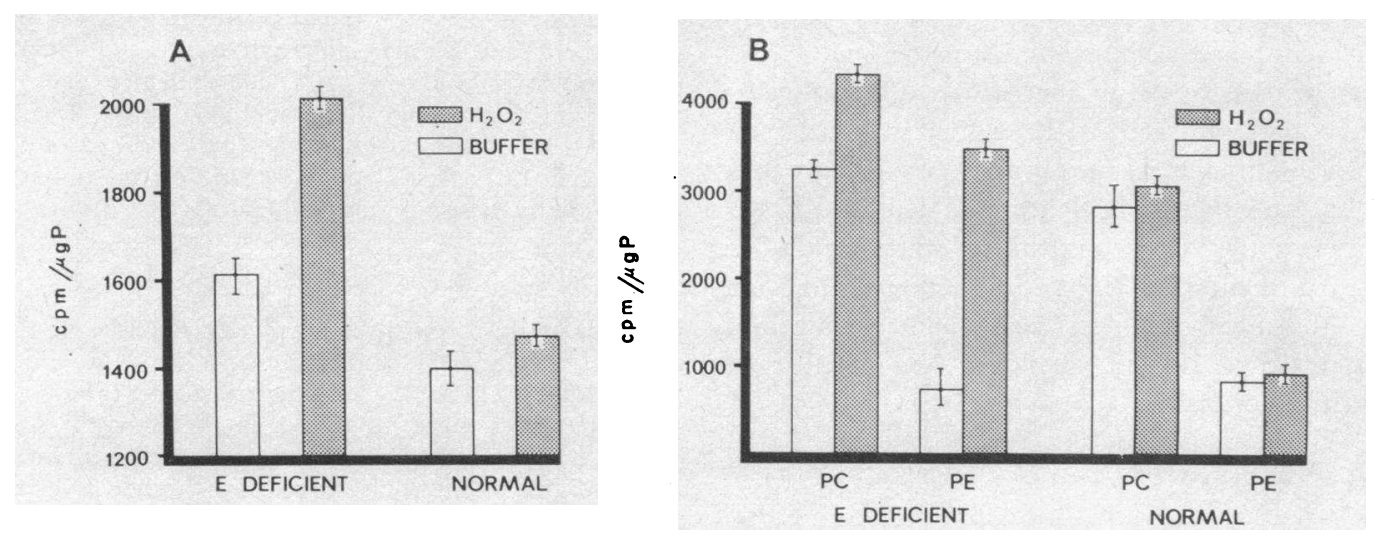

FIGURE 1 Influence of hydrogen peroxide on the incorporation of fatty acid into normal and vitamin $\mathrm{E}$-deficient red blood cells. The cells were incubated with linoleic- $1-{ }^{14} \mathrm{C}$ fatty acid for $1 \mathrm{hr}$, extracted, and counted. The results are expressed as counts per minute/microgram lipid phosphorous. Fig. $1 \mathrm{~A}$ represents the total radioactivity incorporated. Fig. $1 \mathrm{~B}$ represents the radioactivity incorporated into phosphatidylcholine and phosphatidylethanolamine. Incubation in buffer is represented by the clear bars, incubation in hydrogen peroxide by the cross-hatched bars. The points in this figure and in all subsequent figures represent average of duplicates. The ranges are indicated by brackets. See Methods section 5 A.

occurred in half of the samples of vitamin E-deficient red cells which were exposed to $1 \% \mathrm{H}_{2} \mathrm{O}_{2}$ (Table I). When present, this loss was predominantly found in PE. PC, PS, phosphatidylinositol, and sphingomyelin were virtually unaffected before lysis. In contrast, the $\mathrm{PE}$ of normal red blood cells was unaffected during incubation in $\mathrm{H}_{2} \mathrm{O}_{2}$ (data not shown).

Influence of $\mathrm{H}_{2} \mathrm{O}_{2}$ on incorporation of fatty acids into red cell phospholipids. A representative study of the incorporation of linoleic acid into normal and vitamin
A

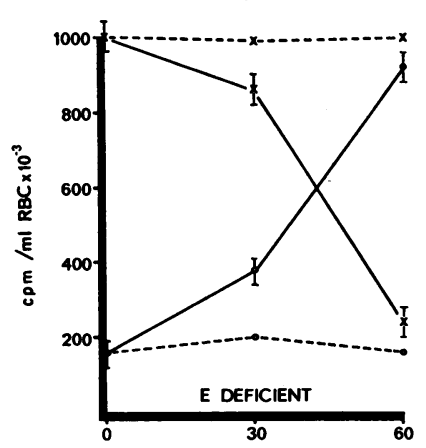

B

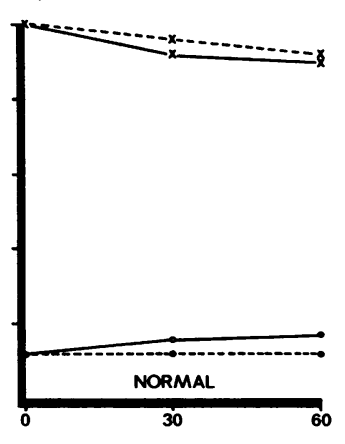

FIGURE 2 Changes in neutral lipid and PE fatty acid after incubation in hydrogen peroxide. Red cells were preincubated with palmitic-1-14 $\mathrm{C}$ fatty acid, washed with saline, and reincubated with hydrogen peroxide. The red cell lipids were extracted, separated by thin-layer chromatography and counted. The radioactivity was expressed as counts per minute/milliliter RBC. Quantitative changes in PE did not occur before lysis in this study. $X=$ counts in neutral lipid; $\mathrm{O}=$ counts in PE. Dotted lines represent incubation in buffer, the solid lines represent incubation in $\mathrm{H}_{2} \mathrm{O}_{2}$. See Methods section $5 \mathrm{~B}$.
E-deficient cells after a $1 \mathrm{hr}$ incubation period is seen in Fig. 1 A. Incubation in buffer alone resulted in a greater total incorporation of fatty acid into the vitamin E-deficient cell than into the normal cell. The addition of $\mathrm{H}_{2} \mathrm{O}_{2}$ to the buffer further stimulated the incorporation of fatty acid into the E-deficient cell but had no effect on the normal cell.

The distribution of incorporated fatty acid is seen in Fig. $1 \mathrm{~B}$. The specific activity of $\mathrm{PE}$ was increased by $\mathrm{H}_{2} \mathrm{O}_{2}$ in the E-deficient cell but was unaffected in the normal cell. In fact most of the increase in total incorporation of fatty acid due to $\mathrm{H}_{2} \mathrm{O}_{2}$ (Fig. $1 \mathrm{~A}$ ) was accounted for by the increase in specific activity of phosphatidylethanolamine shown in Fig. $1 \mathrm{~B}$.

Transfer of fatty acid into $P E$. The transfer of palmitic acid- ${ }^{8} \mathrm{H}$ from neutral lipid into PE (Methods section $5 \mathrm{~B}$ ) is seen in Fig. $2 \mathrm{~A}$ and $2 \mathrm{~B}$. The distribution of radioactivity in the individual lipid classes was determined at 0,30 , and $60 \mathrm{~min}$. In the E-deficient cell (Fig. $2 \mathrm{~A}$ ), fatty acid present in neutral lipid was transferred into $\mathrm{PE}$ during incubation with $\mathrm{H}_{2} \mathrm{O}_{2}$ but not with buffer alone. The total quantity of $\mathrm{PE}$ remained stable during this $60 \mathrm{~min}$ interval. In normal cells (Fig. $2 \mathrm{~B}$ ), $\mathrm{H}_{2} \mathrm{O}_{2}$ did not significantly influence the transfer of fatty acid from neutral lipid to PE.

Effects of removal of radioactivity from the superficial pool of fatty acids upon incorporation of fatty acid into PE. Cells were prepared as described in Methods section of $5 \mathrm{C}$ and incubated (Fig. 3). After replacement of the surface pool of fatty acid with nonradioactive fatty acid, no increment of palmitic acid- ${ }^{8} \mathrm{H}$ could be detected in PE during incubation with or without $\mathrm{H}_{2} \mathrm{O}_{2}$. This result may be contrasted with the ex- 
TABLE I

Prelytic Phospholipid Alterations in E-Deficient Cells Incubated with $\mathrm{H}_{2} \mathrm{O}_{2}$

\begin{tabular}{ccrrrr} 
& \multirow{2}{*}{$\begin{array}{c}\text { Total } \\
\text { lipid } \\
\text { Patients }\end{array}$} & \multicolumn{4}{c}{ Individual phospholipids* } \\
\cline { 3 - 6 } phosphorus & PE & PS-PI & PC & SP \\
\hline 1 & 84 & 63 & 97 & 99 & 100 \\
2 & 100 & 100 & 98 & 99 & 100 \\
3 & 85 & 70 & 99 & 98 & 100 \\
4 & 90 & 80 & 100 & 89 & 100 \\
5 & 100 & 100 & 100 & 99 & 100 \\
6 & 100 & 100 & 100 & 100 & 100 \\
7 & 94 & 88 & 97 & 100 & 100 \\
8 & 100 & 100 & 100 & 99 & 100 \\
\hline
\end{tabular}

The washed red cells were incubated in $\mathrm{KHB}$ with $\mathrm{H}_{2} \mathrm{O}_{2}(1 \%$ final concentration) for $1 \mathrm{hr}$. The media were removed, and the cells were washed with saline before lipid extraction and analysis. All results are expressed as the percentage of the preincubation values of total phospholipid/milliliter red cells. See Methods section $5 \mathrm{~A}$.

* PE, phosphatidylethanolamine; PS-PI, phosphatidylserine, phosphatidylinositol; PC, phosphatidylcholine; SP, sphingomyelin.

periment presented in Fig. $2 \mathrm{~A}$ in which the superficial pool was retained.

Specific activity of saturated and unsaturated $P E$ fatty acid. The change in specific activity of typical $\mathrm{PE}$ fatty acids which occurred when red cells were in-

TABLE II

Specific Activity of Phosphatidylethanolamine after Incubation with Hydrogen Peroxide for 30 min

\begin{tabular}{|c|c|c|c|c|}
\hline & \multicolumn{2}{|c|}{ Saturated fatty acid } & \multicolumn{2}{|c|}{$\begin{array}{l}\text { Unsaturated } \\
\text { fatty acid }\end{array}$} \\
\hline & $\mathrm{H}_{2} \mathrm{O}_{2}$ & Buffer & $\mathrm{H}_{2} \mathrm{O}_{2}$ & Buffer \\
\hline & \multicolumn{2}{|c|}{$c p m / \mu g$ lipid $P$} & \multicolumn{2}{|c|}{$c p m / \mu g$ lipid $P$} \\
\hline E deficient & 3,400 & 400 & 340 & 185 \\
\hline Normal & 365 & 300 & 170 & 170 \\
\hline E deficient & 17,500 & 12,900 & 470 & 390 \\
\hline Normal & 1,000 & 1,400 & 140 & 135 \\
\hline E deficient & 4,730 & 3,180 & 580 & 550 \\
\hline Normal & 1,300 & 1,300 & 170 & 145 \\
\hline E deficient & 5,600 & 900 & 640 & 580 \\
\hline Normal & 1,110 & 1,060 & 250 & 220 \\
\hline E deficient & 7,400 & 1,500 & 970 & 670 \\
\hline Normal & 1,600 & 1,500 & 300 & 290 \\
\hline
\end{tabular}

Red cells were preincubated with saturated fatty acid (palmitic-9, 10- ${ }^{3} \mathrm{H}$ ) and unsaturated fatty acid (arachidonic${ }^{1-14} \mathrm{C}$ ), washed with saline, and reincubated with hydrogen peroxide. The results are expressed as counts per minute/ microgram lipid phosphorous and represent the average of duplicate determinations on blood from five separate patients and controls. See Methods section $5 \mathrm{~A}$.

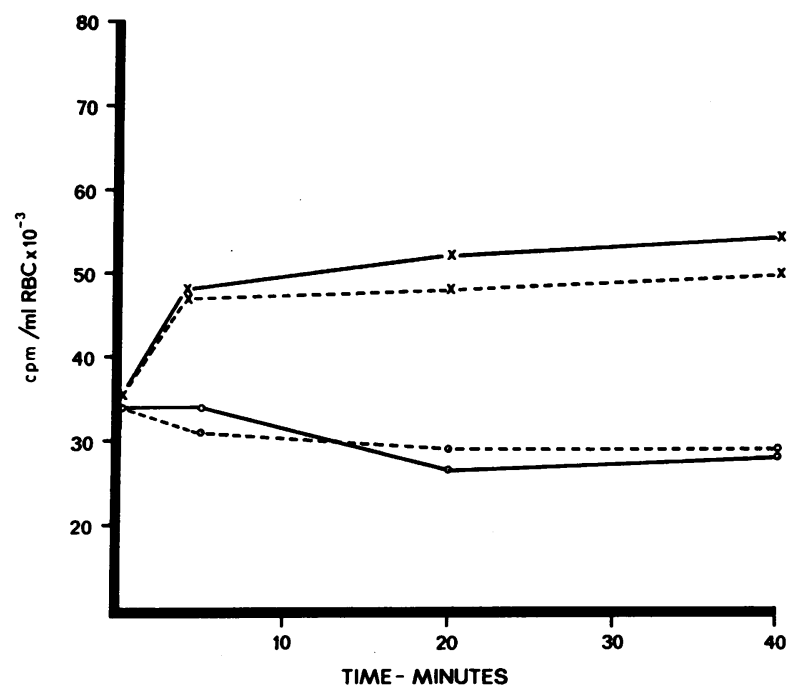

Figure 3 The influence of the albumin extractable lipid pool on changes in phosphatidylethanolamine and neutral lipid fatty acid during incubation in hydrogen peroxide. Vitamin E-deficient cells were preincubated with palmitic$9,10-{ }^{3} \mathrm{H}$ for $2 \mathrm{hr}$ in the presence of glucose. They were washed with saline and defatted albumin to remove the superficial free fatty acid pool (14). A nonradioactive superficial pool was then reintroduced by incubation in autologous serum, and the cells were washed in saline before final reincubation in KHB (---) or in KHB and $2 \%$ hydrogen peroxide (-). The red cell lipids were extracted, isolated by TLC, and counted. The radioactivity isolated is plotted as counts per minute/milliliter RBC. $O=$ counts in neutral lipid; $X=$ counts in PE. See Methods section $5 \mathrm{C}$.

cubated with $\mathrm{H}_{2} \mathrm{O}_{2}$ for $30 \mathrm{~min}$ is seen in Table II. The changes in specific activity of both saturated fatty acid (palmitic acid- ${ }^{8} \mathrm{H}$ ) and an unsaturated FA (arachidonic acid- ${ }^{14} \mathrm{C}$ ) in five separate experiments are recorded. In the E-deficient cell, incubation with $\mathrm{H}_{2} \mathrm{O}_{2}$ caused a much greater increase in specific activity of the saturated fatty acid than of the unsaturated fatty acid. In normal cells, the specific activity of both unsaturated and saturated fatty acid was not significantly changed during the incubation in $\mathrm{H}_{2} \mathrm{O}_{2}$.

The effect of $\mathrm{H}_{3} \mathrm{O}$, on the distribution of fatty acid in $P E$. The influence of $\mathrm{H}_{2} \mathrm{O}_{2}$ on the predominant fatty acid composition in $\mathrm{PE}$ in a typical experiment is seen in Table III (see Methods sections 3 and $5 \mathrm{~B}$ ). Thymol was added at $30 \mathrm{~min}$ in an effort to prevent further changes due to lipid peroxidation. After exposure to $\mathrm{H}_{2} \mathrm{O}_{2}$, the concentration of palmitic acid was increased in the E-deficient cells while the concentration of arachidonic acid was decreased. These alterations were not present in the phosphatidylethanolamine fatty acids of normal cells incubated with $\mathrm{H}_{2} \mathrm{O}_{2}$. Similar results were obtained in four other incubations which are not shown. While the initial concentrations of fatty acids were 
TABLE III

[ Percentage Distribution of Predominant Fatty Acids in E-Deficient and Normal Cell Phosphatidylethanolamine with and without Incubation with $\mathrm{H}_{2} \mathrm{O}_{2}$

\begin{tabular}{lrrrrr}
\hline & \multicolumn{2}{c}{ Patient* } & & \multicolumn{2}{c}{ Control } \\
\cline { 2 - 3 } \cline { 5 - 6 } & Buffer & $\mathrm{H}_{2} \mathrm{O}_{2}$ & & Buffer & $\mathrm{H}_{2} \mathrm{O}_{2}$ \\
\hline $16: 0$ & 17 & 24 & & 14 & 15 \\
$18: 0+18: 1$ DMA & 16 & 18 & & 13 & 12 \\
$18: 1$ & 20 & 21 & & 18 & 17 \\
$18: 2$ & 7 & 6 & & 6 & 6 \\
$20: 4$ & 20 & 13 & & 23 & 24 \\
$22: 4-6$ & 15 & 11 & & 18 & 16
\end{tabular}

After incubation of red cells in buffer with $1 \% \mathrm{H}_{2} \mathrm{O}_{2}$ for $45 \mathrm{~min}$, saturated thymol was added to inhibit further peroxidation. Hemolysis had not occurred at this time. After extraction and separation, PE fatty acids were determined by TLC. Total PE did not change during the time of these observations $( \pm 4 \%)$. No major or consistent changes in saturation were detected in the remaining minor fatty acids. The experiment shown here is representative of five similar incubations. See Methods sections 3 and $5 \mathrm{~A}$.

* All data are expressed as percentage of total fatty acids present (determined from the sum of the gas chromatography peaks corrected for molecular weights).

variable due to the differing ages and types of disease of the donor patients, in all cases there was an increase in the amount of 16:0 and 18:0 saturated fatty acids and a decrease in polyunsaturated fatty acids after exposure to $\mathrm{H}_{2} \mathrm{O}_{2}$.

\section{DISCUSSION}

In 1952, Rose and Gyorgy (13) described the hemolytic effect of $\mathrm{H}_{2} \mathrm{O}_{2}$ on vitamin $\mathrm{E}$-deficient red blood cells. The mechanism of this event is still not completely understood. In the absence of vitamin $E$ or a similar antioxidant, phosphatide unsaturated fatty acids are peroxidized with resultant schism of the fatty chains (20). The residual esterified short acyl fragment would then tend to escape from its previously protected hydrophobic environment (21). It would then be especially susceptible to removal by an endogenous erythrocyte phospholipase (22). The resultant lysophosphatidylethanolamine might then be lost to the medium due to its high water solubility or it might be reacylated within the membrane $(14,23,24)$. PE containing a high percentage of unsaturated fatty acids is particularly susceptible to peroxide alterations (6). In vitamin E-deficient erythrocytes from rats and patients with A- $\beta$ lipoproteinemia, prelytic loss of $\mathrm{PE}$ has been associated with hemolysis $(3,4)$. In addition, products of the peroxidation of unsaturated fatty acids also inhibit sul- fydryl-containing enzymes and may potentiate membrane damage (25).

The present study was undertaken to investigate further the influence of $\mathrm{H}_{2} \mathrm{O}_{2}$ on human vitamin $\mathrm{E}$ deficient red cells. In addition to examining quantitative changes in individual phosphatides, the influence of $\mathrm{H}_{2} \mathrm{O}_{2}$ on the incorporation and turnover of fatty acids within red cell lipid classes, specifically $\mathrm{PE}$, was determined.

Studies on red cells from six vitamin E-deficient patients indicated that prelytic loss of phospholipid was not essential for hemolysis during incubation with $\mathrm{H}_{2} \mathrm{O}_{2}$ (Table I). When phospholipid loss was present, it was confined to PE. The degree of vitamin $\mathrm{E}$ deficiency in previously reported studies in rodents may have been more profound than that seen in the children in this study and may account for the observed consistent prelytic loss of PE in those studies (3).

The incorporation of fatty acids into vitamin E-deficient red blood cells without $\mathrm{H}_{2} \mathrm{O}_{2}$ was greater than that into normal cells. This difference may be explained by red cell age alone. The reticulocyte counts in the $\mathrm{E}$ deficient cells ranged from $4 \%$ to $6 \%$ while the reticulocyte counts in the normal cells were $2 \%$ or less. Young red cells incorporate fatty acid at a greater rate than do old cells (26). However, $\mathrm{H}_{2} \mathrm{O}_{2}$ further stimulated the incorporation of fatty acid into E-deficient cells but had no effect on the incorporation of fatty acid into normal cells (Fig. 1) (27) or into normal reticulocytes (data not shown). Fig. $1 \mathrm{~B}$ shows that the $\mathrm{H}_{2} \mathrm{O}_{2}$-stimulated increase in fatty acid incorporation was confined to $\mathrm{PE}$. Since the quantity of $\mathrm{PE}$ was not changed, the increase in radioactivity indicates an increased turnover of fatty acid in $\mathrm{PE}$.

The data in Fig. 2 and Table II demonstrate that there is a transfer of both saturated and unsaturated fatty acid from neutral lipid into PE. The data in Fig. 3 show that this transfer is dependent upon the neutral lipid precursor pool (14). This transfer is stimulated in the E-deficient cell by incubation in $\mathrm{H}_{2} \mathrm{O}_{2}$ and can occur before hemolysis. The final accumulation of saturated fatty acid is far greater than unsaturated fatty acid (Table II). This difference may be explained by the specific susceptibility of unsaturated fatty acid to $\mathrm{H}_{2} \mathrm{O}_{2}$ in contrast to saturated fatty acid: while reacylation of both unsaturated and saturated fatty acid may occur, the newly acquired unsaturated fatty acid continues to be at risk to ongoing peroxidation, whereas the newly acquired saturated fatty acid is resistant. Hence, saturated fatty acid accumulates. The cumulative effect of these processes is a remodeling of red cell $\mathrm{PE}$ in terms of its fatty acid composition.

Fatty acid analytic data (Table III) confirmed these radioactivity measurements by showing a decrease in 
the percentage of the predominant unsaturated fatty acids in $\mathrm{PE}$ after incubation with $\mathrm{H}_{2} \mathrm{O}_{2}$. Since the amount of total phospholipid did not change during these experiments, these percentage shifts reflect changes in the absolute amounts of PE fatty acid as well. The extent of these changes is surprisingly high for the brief period of incubation used. This may be due to both the general stimulation of acylation reactions previously observed in buffer systems $(23,24)$ and to the specific stimulation of $\mathrm{PE}$ fatty acid turnover observed under the influence of $\mathrm{H}_{2} \mathrm{O}_{2}$ here (see Fig. $1 \mathrm{~B}$ ). Also, remotely, the thymol treatment used to inhibit peroxidation may have not totally terminated the process, and some turnover may have continued until the time of lipid extraction. All of these factors limit quantitative extrapolation from the extent of these in vitro observations to in vivo situations. However, the qualitative trend indicated by these observations is entirely consistent with the previous in vivo observations of Jacob and Lux (3).

When E-deficient cells previously labeled with radioactive fatty acid were washed with defatted albumin and reincubated in serum to reestablish a nonradioactive superficial pool, the transfer of radioactively labeled fatty acid from neutral lipid into $\mathrm{PE}$ was not observed. As expected, this was probably due to the removal of radioactivity from the superficial fatty acid pool and indicates that this pool provides the fatty acid for the repair process stimulated by $\mathrm{H}_{2} \mathrm{O}_{2}$.

Alterations in the permeability of experimental lipid membranes can occur with qualitative or quantitative changes in their lipid components. Studies performed on artificially prepared lipid micelles have shown increased sodium permeability when the content of linoleic acid was decreased (28). Variations in cation permeability in mammalian red cells may also reflect specific changes in fatty acid concentration (29). By analogy, the alterations seen here in the composition of fatty acid in erythrocyte $\mathrm{PE}$ might be expected to alter red cell permeability. This expectation has been born out by observations of increased permeability and decreased cation content in vitamin E-deficient erythrocytes after exposure to hydrogen peroxide but before hemolysis. These changes, which occur simultaneously with the membrane lipid changes just described, will be the subject of a further report.

\section{ACKNOWLEDGMENTS}

The authors are grateful to Dr. Manfred L. Karnovsky for stimulating discussion.

This study was supported by U. S. Public Health Service grants HD-02777 and AM-05581.

\section{REFERENCES}

1. Dormandy, T. L. 1969. Biological rancidification. Lancet. 2: 684 .

2. Tappel, A. L. 1962. Vitamin $\mathrm{E}$ as the biological lipid antioxidant. Vitamins Hormones. 20: 493.

3. Jacob, H. S., and S. E. Lux. 1968. Degradation of membrane phospholipid and thials in peroxide hemolysis: studies in vitamin E deficiency. Blood. 32: 549.

4. Dodge, J. T., G. Cohen, H. J. Kayden, and G. B. Phillips. 1967. Peroxide hemolysis of red blood cells from patients with abetalipoproteinemia (acanthocytosis). J. Clin. Invest. 46: 357.

5. Younkin, S., F. A. Oski, and L. A. Barness. 1971. Mechanism of dehydrogen peroxide hemolysis test and its reversal with phenols. Amer. J. Clin. Nutr. 24: 7.

6. Dodge, J. T., and G. B. Phillips. 1967. Composition of phospholipids and of phospholipid fatty acids and aldelydes in human red cells. J. Lipid Res. 8: 667.

7. Shohet, S. B. 1970. Release of phospholipid fatty acid from human erythrocytes. J. Clin. Invest. 49: 1668.

8. Shohet, S. B., and D. G. Nathan. 1970. Incorporation of phosphatide precursers from serum into erythrocytes. Biochim. Biophys. Acta. 202: 202.

9. Chen, R. F. 1967. Removal of fatty acids from serum albumin by charcoal treatment. J. Biol. Chem. 242: 173.

10. Filer, L. J., S. W. Wright, M. P. Manning, and K. E. Mason. 1951. Absorption of alpha tocopherol and tocopheryl esters by premature and full-term infants and children in health and disease. Pediatrics. 8: 328.

11. Nitowski, H. M., H. H. Gordon, and J. T. Tildon. 1956. Studies of tocopherol deficiency in infants and children. IV. The effect of alpha tocopherol on creatinuria in patients with cystic fibrosis of the pancreas and biliary atresia. Bull. Johns Hopkins Hosp. 98: 361.

12. Oski, F. A., and L. A. Barnes. 1967. Vitamin E deficiency: a previously unrecognized cause of hemolytic anemia in the premature infant. J. Pediat. 70: 211.

13. Rose, C. S., and P. Gyorgy. 1952. Specificity of the hemolytic reaction in vitamin $\mathrm{E}$ deficient erythrocytes. Amer. J. Physiol. 168 : 414.

14. Shohet, S. B., D. G. Nathan, and M. L. Karnovsky. 1968. Stages in the incorporation of fatty acids into red blood cells. J. Clin. Invest. 47: 1096.

15. Parker, F., and N. F. Peterson. 1967. Quantitative analysis of phospholipids and phospholipid fatty acids from silica gel thin-layer chromatograms. J. Lipid Res. 6: 455.

16. Snyder, F., and N. Stephens. 1962. Quantitative carbon14 and tritium assay of thin-layer chromatography plates. Anal. Biochem. $4: 128$.

17. Morrison, W. R., and L. M. Smith. 1964. Preparation of fatty acid methyl esters and dimithylacetals from lipids with boron fluoride-methanol. J. Lipid Res. 5: 600.

18. Buhler, D. R. 1962. A simple scintillation counting technique for assaying $\mathrm{C}^{14} \mathrm{O}_{2}$ in a Warburg flask. Anal. Biochem. 4 : 413.

19. Skipski, V. P., J. J. Good, M. Barclay, and R. B. Reggio. 1968. Quantitative analysis of simple lipid dosses by thin-layer chromatography. Biochim. Biophys. Acta. 152 : 10.

20. Mengel, C. E. 1968. Rancidity of the red cell. Peroxidation of red cell lipid. Amer. J. Med. Sci. 255: 341.

21. Victoria, E. J., and A. A. Barber. 1969. Peroxidation of microsomal membrane protein lipid complexes. Lipids. 4: 582.

22. Paysant, M., M. Bitran, R. Wald, and J. Polonovsky. 
1970. Phospholipase A des globules rouges chez l'homme: action sur les phospholipides endogenes et exogenes. Bull. Soc. Chim. Biol. 52: 1257.

23. Oliveira, M. M., and M. Vaughan. 1964. Incorporation of fatty acids into phospholipids of erythrocyte membranes. J. Lipid Res. 5 : 156.

24. Mulder, E., and L. L. M. Van Deenen. 1965. Metabolism of red cell lipids. I. Incorporation in vitro of fatty acids into phospholipids from mature erythrocytes. Biochim. Biophys. Acta. 106: 106.

25. Lewis, S. E., and D. D. Wills. 1962. The destruction of $\mathrm{SH}$ groups of proteins and amino acids by peroxides of unsaturated fatty acids. Biochem. Pharmacol. 11: 901.
26. Winterbourn, C. C., and R. D. Batt. 1970. The uptake of plasma fatty acids into human red cells and its relation to cell age. Biochim. Biophys. Acta. 202: 9.

27. Wittels, B. 1970. Modification of phospholipid metabolism in human red cells by primaquine. A possible mechanism in drug induced hemolytic anemia. Biochim. Biophys. Acta. 210: 74.

28. Moore, J. L., T. Richardson, and H. F. DeLuca. 1969. Essential fatty acids and ionic permeability of lecithin membranes. Chem. Phys. Lipids. 3 : 39.

29. Kogl, F., J. DeGier, I. Mulder, and L. L. M. Van Deenen. 1960. Metabolism and functions of phosphatides: specific fatty acid composition of the red blood cell membranes. Biochim. Biophys. Acta. 43: 95. 